\title{
Acute Fulminant Hepatic Failure, Encephalopathy and Early CT Changes
}

\author{
Sathees Waran Thayapararajah, Irene Gulka, Ahmed Al-Amri, Sujut Das, \\ G. Bryan Young
}

\begin{abstract}
Background: Acute fulminant hepatic failure (AFHF) is common in tertiary care centres with transplant facilities. Cerebral edema frequently threatens the lives of such patients. We reviewed our cases of AFHF, noting the incidence of cerebral edema with serial CT scans and factors associated with mortality. Methods: Patients were captured through HMRI classification of acute liver/hepatic failure. Chart review included tabulation of: demographics, INR; serum bilirubin, creatinine, albumin; in-hospital mortality. Computed tomogram (CT) scans were re-read with blinding to clinical information and catalogued for changes in sulcal markings, ventricular size and grey-white differentiation (GWD). Inclusion criteria: age equal to or greater than 16 years, encephalopathy, hepatic failure within eight weeks of onset of liver disease, CT scans of head performed. Results: Of our 25 cases with AFHF, acetaminophen toxicity was the most common etiology (nine cases). Twelve of the 25 patients (48\%) had cerebral edema on CT, including eight of the nine $(89 \%)$ with acetaminophen toxicity. Decrease in sulcal markings and ventricular size preceded conspicuous alterations in GWD. Fourteen died, including all 12 with cerebral edema, although death was due to herniation in only one patient. None of the hematological or biochemical variables correlated significantly with mortality. Conclusions: Acetaminophen toxicity is a common cause of AFHF; this combination has a strong association with cerebral edema. Cerebral edema can be detected in its early stages and followed by baseline and serial CT scans. This facilitates management to prevent fatal brain herniation.
\end{abstract}

RÉSUMÉ: Insuffisance hépatique aiguë fulminante, encéphalopathie et changements précoces au CT. Contexte : L'insuffisance hépatique aiguë fulminante (IHAF) est fréquente dans les centres de soins tertiaires qui possèdent des unités de transplantation. L'œè̀me cérébral met fréquemment la vie de ces patients en danger. Nous avons revu nos cas d'IHAF et noté l'incidence d'œdème cérébral à la tomodensitométrie cérébrale sériée ainsi que les facteurs associés à la mortalité. Méthode : Nous avons identifié les patients au moyen de la classification HMRI de l'insuffisance hépatique aiguë. Nous avons relevé dans leurs dossiers les données démographiques, l'INR, la bilirubine sérique, la créatinine, l'albumine et la mortalité hospitalière. Les tomodensitométries ont été relues à l'aveugle quant aux données cliniques et répertoriés selon les changements de la trame des scissures, la taille des ventricules et le contraste entre la substance grise et la substance blanche (CGB). Les critères d'inclusion étaient les suivants : l'âge $\geq 16$ ans, l'encéphalopathie, l'insuffisance hépatique survenant dans les 8 semaines suivant le début de la maladie hépatique et une tomodensitométries de la tête. Résultats : Chez nos 25 patients atteints d'IHAF, l'intoxication par l'acétaminophène était l'étiologie la plus fréquente, soit chez 9 patients. Douze des 25 patients $(48 \%)$ présentaient de l'œdème cérébral à la tomodensitométrie, dont 8 des 9 patients $(89 \%)$ présentant une intoxication à l'acétaminophen. Une diminution des repères des sillons et de la taille des ventricules précédait les altérations évidentes du CGB. Quatorze patients sont décédés dont les 12 patients qui présentaient de l'œdème cérébral. À noter que la mort était due à une hernie du tissu cérébral à travers le trou occipital. Aucune des variables hématologiques ou biochimiques n'était corrélée de façon significative à la mortalité. Conclusions : La toxicité à l'acétaminophen est une cause fréquente d'IHAF et est fortement associée à l'œdème cérébral. L'œdème cérébral peut être détecté à un stade précoce de la maladie et le suivi peut être fait par la tomodensitométrie effectuée au début de la maladie et en série par la suite. Ceci facilite le traitement et permet d'éviter une hernie cérébrale fatale.

Can J Neurol Sci. 2013; 40: 553-557

Acute fulminant hepatic failure (AFHF) is characterized by the rapid development of severe hepatic parenchyma injury, leading to development of jaundice, coagulopathy and hepatic encephalopathy (HE) within eight weeks with previously normal liver or well-compensated liver disease. Principal etiologies include acetaminophen overdose (AOD), autoimmune hepatitis, viral hepatitis, mushroom poisoning and alcohol abuse. ${ }^{1}$ In 15 to $20 \%$ of cases the cause is unknown. ${ }^{1}$ In contrast to patients with chronic hepatic failure, AFHF is often accompanied by cerebral edema, with the potential for raised intracranial pressure and death or later morbidity. ${ }^{2-4}$ The exact mechanism by which the cerebral edema occurs is unknown, but ammonia is still thought to play a key role. More recently, the "Trojan horse hypothesis" proposes that, within the brain, ammonia is converted into glutamine, glutamine then enters astrocytic mitochondria and is metabolized back to glutamate and ammonia. ${ }^{1}$ Intramitochondrial ammonia contributes to reactive oxygen species, which increase mitochondrial permeability and activate kinases, leading to astrocytic swelling. A fatal outcome or severe brain damage may be prevented by the prompt and judicious

From the Department of Clinical Neurological Sciences, University of Western Ontario, London, Ontario, Canada.

Received October 9, 2012. Final Revisions Submitted January 4, 2013. Correspondence to: G.B. Young, Room B10-106, Department of Clinical Neurological Sciences, University Hospital, 339 Windermere Road, London, Ontario, N6A 5A5, Canada. Email: bryan.young@lhsc.on.ca. 
institution of mannitol or hypertonic saline, hypothermia and, in the most severe cases, hepatic transplantation. ${ }^{5-7}$ The Molecular Adsorbents Recirculating System (MARS) may be of help in correcting biochemical derangements in the plasma. ${ }^{8,9}$ Early detection and monitoring the course of cerebral edema is, thus, of great importance. Since coagulopathy often precludes direct measurement of intracranial pressure (ICP), we sought to determine if surrogate tests computed tomography (CT) head scans and biochemical data) could be used to detect and monitor cerebral edema and correlated their results with mortality.

\section{Methods}

\section{Patient data}

The University of Western Ontario Ethics Review Board approved our study. Our goal was to identify changes of cerebral edema on CT and to examine CT and baseline biochemical laboratory data with respect to patient survival. The study was retrospective but included all patients with AFHF from January 1, 2004 - January 31, 2008. We included: a) patients of 16 yearsof-age or greater who developed elevated international normalized ratio (INR) as an index of coagulopathy and encephalopathy from hepatocellular disease within eight weeks of the onset of liver disease; and b) those who had initial CT head scans within 24 hours from admission to hospital. We excluded patients with missing data or those whose scans were delayed. We examined the patients' baseline laboratory data and CT of brain with AFHF and graded the encephalopathy using Lockwood's grading scale (Table 1).

\section{Computed tomography neuro-imaging analysis}

The study protocol defined cerebral edema by noting specifically selected grey-white matter differentiation, ventricular size, cortical sulcal narrowing or effacement, diencephalic, uncal and tonsillar herniation, basal cistern changes, brain stem hemorrhagic changes and atrophy. The radiologist (IG) examined serial scans of each patient, noting if changes occurred. Initial and subsequent scans were then compared for each patient. Patients were assigned codes and the neuroradiologist was blinded to patient identity, but was given the patients' ages. There were no quantitative measurements. For ventricular size the scans were compared to note if the diameter of the ventricles, especially the lateral and third ventricles, decreased. Similarly, changes in the width of sulci and the distinction of grey and white matter were compared on serial scans.

\section{Biochemical laboratory variables}

We have selected the following variables: internationalized normalized ratio (INR), serum bilirubin, creatinine and albumin (SI units). These are clinically relevant laboratory variables in AFHF and are utilized by many scoring systems (Model for Endstage Liver Disease (MELD), King's College Hospital criteria, Pediatric End-Stage Liver disease (PELD) and Child-TurcottePugh (CTP) score) for prognostic determination ${ }^{7-9}$. We collected only initial (baseline) screening laboratory values for the study; all were obtained prior to starting them in medical therapy.

\section{Statistical treatment}

Multivariate logistic regression was used to evaluate an association among the clinical variables obtained from CT observations and laboratory tests. The sensitivity of various CT parameters in showing change (cerebral edema) were compared with the grade of encephalopathy (Table 1) using logistic regression analysis to create odds ratios (ORs). The comparison of various CT parameters with each other for detecting early cerebral edema was used to create odds ratios without logistic regression. The relationships of INR and various biochemical tests to patient outcomes (survived or died) were compared using the two-tailed Student t-test. Statistical Analysis Software (SAS) 9.2 version program was used for data analysis.

\section{RESULTS}

Twenty-five patients (16 were women), met our criteria; of these nine (36\%) had AOD (six were women) aged 17-39 years. Other causes: alcoholic hepatitis (3), auto-immune hepatitis (1), viral hepatitis (1), multiple toxins (1), valproate-induced hepatic

Table 1: Neurological and neuropsychiatric abnormalities related to severity of hepatic encephalopathy

\begin{tabular}{|c|c|c|c|c|}
\hline Clinical Parameter & Grade I & Grade II & Grade III & Grade IV \\
\hline Consciousness & Alert, mild inattention & Blunting & $\begin{array}{l}\text { Stuporous but } \\
\text { rousable }\end{array}$ & Comatose \\
\hline Behavior & $\begin{array}{l}\text { Reversal of sleep pattern; } \\
\text { irritable; depressed }\end{array}$ & $\begin{array}{l}\text { Apathy; lethargy; } \\
\text { disinhibition; anxious }\end{array}$ & Paranoia & - \\
\hline Affect & Labile & Labile & Blunted & - \\
\hline Cognition & Impaired visuomotor skills & Delirium & Too impaired to test & - \\
\hline Neurological exam & $\begin{array}{l}\text { Postural-action tremor, } \\
\text { asterixis, multifocal } \\
\text { myoclonus; increased DTRs }\end{array}$ & $\begin{array}{l}\text { Frontal release signs; } \\
\text { gegenhalten; } \\
\text { dysarthria; ataxic gait; } \\
\text { parkinsonism }\end{array}$ & $\begin{array}{l}\text { Dilated pupils; } \\
\text { nystagmus }\end{array}$ & $\begin{array}{l}\text { Spasticity; clonus extensor } \\
\text { plantar responses, decorticate/ } \\
\text { decerebrate; abnormal EOMs }\end{array}$ \\
\hline
\end{tabular}

(adapted from Lockwood AH/ Toxic and Metabolic Encephalopathies. In: Bradley WG, Daroff RB, Fenichel G, et al., (Eds.)

Neurology in Clinical Practice. Boston:Butterworth Heinemann. DTRs = deep tendon reflexes; EOMs = extraocular movements 
Table 2: Initial brain parenchyma changes on computed tomography observed under all etiologies with respect to acute fulminant hepatic failure

\begin{tabular}{lll}
\hline Variable & Odds ratio $(95 \% \mathrm{CI})$ & p value \\
\hline GWD & $2.04(1.26-3.31)$ & 0.004 \\
SN & $2.01(1.25-3.23)$ & 0.004 \\
VS & $1.44(1.02-2.04)$ & 0.037 \\
UH & $1.18(0.76-2.13)$ & 0.571 \\
TH & $1.18(0.76-2.13)$ & 0.571 \\
BC & $1.18(0.76-2.13)$ & 0.571 \\
DH & $1.37(0.78-2.41)$ & 0.267 \\
\hline
\end{tabular}

$\mathrm{BC}=$ Basal cistern changes, $\mathrm{CI}=$ confidence interval, $\mathrm{DH}=$ diencephalic herniation, GWD = grey white matter differentiation, $\mathrm{UH}=$ Uncal herniation, $\mathrm{TH}=$ Tonsillar herniation, $\mathrm{VS}=$ ventricular size, $\mathrm{SN}=$ sulcal narrowing,

failure (1), Wilson's disease (1), Budd-Chiari syndrome (1), multi-organ failure (1), 6 had unknown etiology. Fourteen patients, of whom $10(71 \%)$ were women, died. Of the 14 patients who died, only one succumbed to cerebral edema and herniation. Seven patients died of liver failure ( \pm renal or pulmonary complications). Three died of pulmonary complications and two from cardiac arrhythmias. One patient died of disseminated Aspergillosis shortly after second hepatic transplantation. Patients were managed vigorously and promptly in ICU.

\section{Neuroradiological investigation and analysis}

Treatment with mannitol/hypertonic saline and hypothermia was instituted as soon as cerebral edema was noted on CT scans by the reporting radiologist on 12 of the 25 patients.

Out of 25 patients, 12 had grey-white matter differentiation (GWD) changes, changes of ventricular size and sulcal narrowing. Three variables, GWD, sulcal narrowing and ventricular size showed significant changes with acetaminophen overdose.

Within the 24 hours of overdose of acetaminophen the most common changes were observed with GWD on neuroimaging studies. Grey-white matter differentiation was 34 times more likely to show changes with acetaminophen overdose patients. Patients with acetaminophen overdose were 24 times more likely to develop for cerebral edema than non acetaminophen overdose patients. Other independent variables have not shown any significant difference. The greatest number of changes observed with AOD (Table 2 vs. Table 3 ).

Logistic regression analysis of neuroimaging results showed that AFHF patients develop the changes on brain parenchyma within 24 hours of onset of symptoms, during Grade I-II encephalopathy, most strikingly with AOD. Considering all etiologies, the ratio was $2.04(95 \% \mathrm{CI}=1.26-3.31 ; \mathrm{p}<0.004)$ for changes on grey-white matter differentiation over other CT parameters (Table 2). However, with AOD, the ratio was significantly higher $(\mathrm{OR}=34.0 ; 95 \% \mathrm{CI}=3.07-393.18 ; \mathrm{P}<0.003)$. There was also a significant association with AOD and
Table 3: Initial brain parenchyma changes on computed tomography for acetaminophen overdose

\begin{tabular}{llll}
\hline Variable & \multicolumn{2}{l}{ Odds ratio $(95 \% \mathrm{CI})$} & $\mathrm{p}$ value \\
GWD & 34.70 & $(3.07-393.18)$ & 0.004 \\
CE & 7.71 & $(1.59-51.17)$ & 0.008 \\
VS & 24.0 & $(2.25-255.94)$ & 0.033 \\
UH & $1.87(0.10-34.13)$ & 0.671 \\
TH & 1.87 & $(0.10-34.13)$ & 0.671 \\
BC & 1.87 & $(0.10-34.13)$ & 0.671 \\
DH & 4.37 & $(0.33-55.58)$ & 0.266 \\
\hline
\end{tabular}

$\mathrm{GWD}=$ grey white matter differentiation, $\mathrm{VS}=$ ventricular size, $\mathrm{CE}=$ cerebral edema, $\mathrm{DH}=$ Diencephalon herniation, $\mathrm{UH}=$ Uncal herniation, $\mathrm{TH}=$ Tonsillar herniation, $\mathrm{BC}=\mathrm{Basal}$ cistern changes, $\mathrm{CI}=$ confidence Interval.

ventricular size changes $(\mathrm{OR}=24 ; 95 \% \mathrm{CI}=2.25-255.94 ; \mathrm{P}<$ $0.037)$ and mild form of cerebral edema development $(\mathrm{OR}=7.71$; 95\% CI=1.59-51.17; P< 0.004), (Table 3). At Grade I or II encephalopathy, considering all etiologies including AOD, we did not find initial significant CT changes on the following: diencephalic herniation ( $\mathrm{p}$ value $=0.267$ and 0.266 ), uncal herniation ( $\mathrm{p}$ value $=0.571$ and 0.671$)$, tonsillar herniation $(\mathrm{p}$ value $=0.571$ and 0.671), and basal cistern changes ( $p$ value $=0.571$ and 0.671$)$, (Tables 2 and 3 ).

\section{Biochemical laboratory values}

Our analysis shows that initial (baseline) total bilirubin, creatinine and albumin (all with $\mathrm{p}$ values $>0.05$ ) did not have significant association with patient outcome (Table 4). However, non survivors had much lower median INR (4.8 SD +/- 2.2 vs. $6.9+/-2.6)$ than survivors. This apparent paradox may be explained by prompt liver transplantation in cases with markedly raised INR values. All the survivors with the AOD group had liver transplantation as the major therapeutic intervention.

\section{DISCUSSION}

Wijdicks and colleagues examined cerebral edema on CT scans and correlated this with the severity of encephalopathy in patients with acute hepatic failure. ${ }^{10}$ Their scoring system for cerebral edema was, however, preconceived and arbitrary, giving maximal points (6) to loss of cerebral sulci. We found that loss of grey-white differentiation was as sensitive an indicator of cerebral edema. Wijdicks and colleagues rated each grey-white interface as 2 (for vertex, internal capsule and centrum semiovale), while we considered any loss of grey-white differentiation. Thus, the sensitivity of CT to encephalopathy in the system by Wijdicks et al was low until patients were in deep coma with posturing. We contend that analysis should not be so weighted, but to use the earliest features of cerebral edema. We found this to be loss of grey-white differentiation, but the interpretation relies on a qualified neuroradiologist. Our study yielded a sensitive method that correlated with and prompted 
Table 4: Laboratory Mean Values for 25 Patients with AFHF

\begin{tabular}{c|c|c|c|c}
\hline Neuro-Imaging & Total Bilirubin Micromols/L (SD) & INR (SD) & Creatinine (SD) & Albumin g/L (SD) \\
\hline GWD & & & & \\
\hline none & $237.3(228)$ & $4.6(3.4)$ & $262.8(143.8)$ & $26.6(5.8)$ \\
\hline change & $198.4(214.5)$ & $5.5(2.7)$ & $202.9(154.7)$ & $19.5(6.6)$ \\
\hline SULCAL NARROWING & & & & \\
\hline no changes & $245.2(193.2)$ & $4.3(5.8)$ & $278.6(190.8)$ & $26.5(29.3)$ \\
\hline change & $193.2(205.4)$ & $5.8(2.7)$ & $190.8(153.3)$ & $29.3(6.3)$ \\
\hline VENTRICULAR SIZE & & & & \\
\hline no change & $241.2(235.4)$ & $4.7(3.4)$ & $267.5(151.4)$ & $26.4(5.0)$ \\
\hline change & $197.5(206.3)$ & $5.3(2.8)$ & $202.8(144.4)$ & $29.4(7.2)$ \\
\hline
\end{tabular}

treatment at Grade I-II encephalopathy with hyperosmolar therapy and hypothermia, and may have led to a decreased incidence of death from herniation or ischemic changes from raised intracranial pressure (ICP) and decreased perfusion pressure. Baseline and subsequent CTs of brain allow for early detection of cerebral edema and may prompt steps to prevent rapid progression of cerebral edema, which has a high mortality rate. Without initial intervention at grade 1 or 2 of hepatic encephalopathy, and progression to higher grades, the probability of a good prognosis is extremely low. ${ }^{6}$

Eight of nine AOD patients developed a mild form of cerebral edema $(\mathrm{OR}=7.71 ; 95 \% \mathrm{CI}=1.59-51.17 ; \mathrm{P}<0.004)$ and greywhite matter differentiation changes $(\mathrm{OR}=34.0 ; 95 \% \mathrm{CI}=3.07$ 393.18; $\mathrm{P}<0.003)$ during the early stages of their illness. This is noteworthy, considering that $\mathrm{CT}$ of the brain is not considered as initial procedure in AOD patients. ${ }^{11}$ Computed tomogram of head is most often used to exclude other causes of decline in mental status, such as intracranial hemorrhage or mass lesion. Our finding strongly supports performing a CT head scan on
AOD patients as soon as they are admitted, to serve as a baseline for subsequent scans. Recognizing specific changes provides an opportunity to prevent the progression of severe form of cerebral edema (Figures A-C). Acetaminophen overdose cases may constitute a special group at risk of developing cerebral edema earlier in the course of AFHF. This is supported by a study in rats, in which acetaminophen produced more marked cerebral cortical edema than was found in rats with hyperammonemia from partial portal vein ligation. ${ }^{12}$

Although the American Association for the Study of Liver Diseases recommends ICP monitoring for $\mathrm{AFHF}^{11}$, such invasive monitoring is associated with intracerebral hemorrhages in $10-20 \%$ of $\operatorname{cases}^{13}$. Intracranial pressure monitoring procedure becomes virtually impossible to perform on patients with high INR. Furthermore, the 30 day survival rate was the same in monitored compared to unmonitored patients in a retrospective survey ${ }^{13}$. The ICP monitoring is invasive and is usually performed in patients with Grade III-IV encephalopathy, in whom cerebral edema is present in 75 to $80 \%$ of patients ${ }^{13}$.
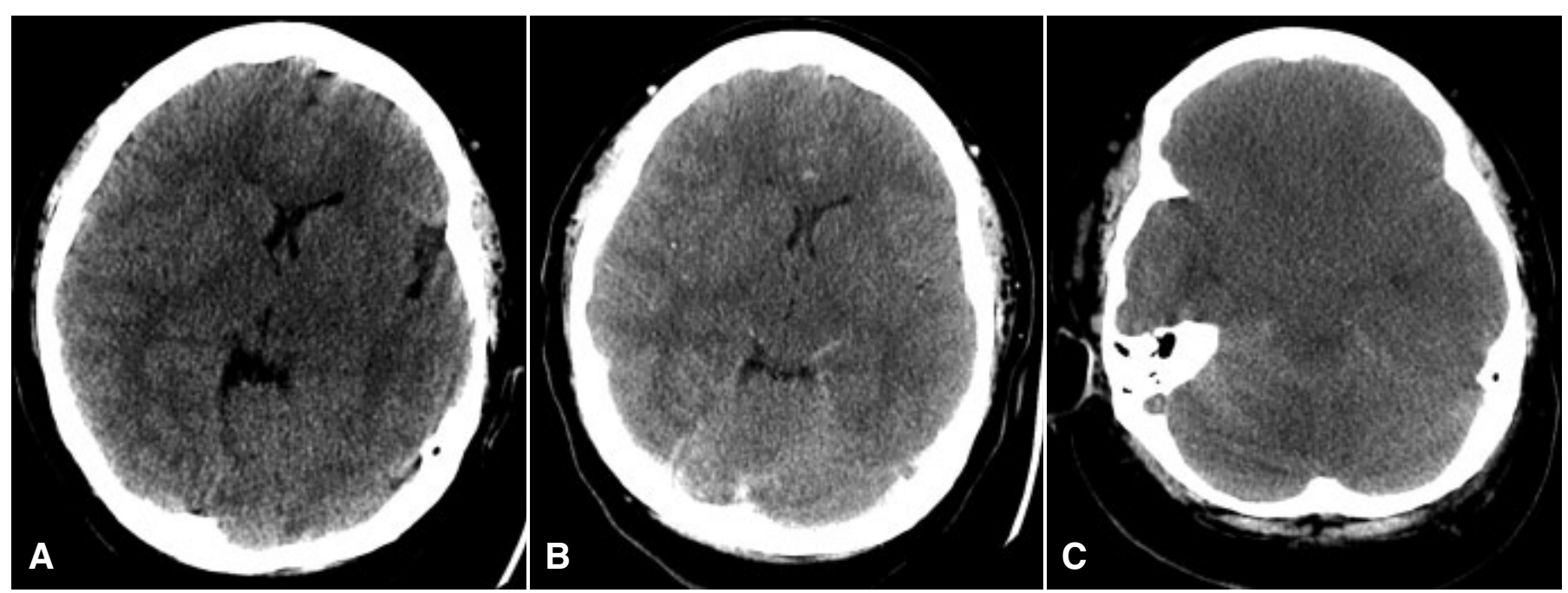

Figures: A-C) 30-year-old woman with an acetaminophen overdose. A) is a CT taken within 24 hours of acetaminophen overdose, while the patient was delirious: the grey-white differentiation is poor and sulci are narrow. B) twenty-four hours later the ventricles are narrower and the sulci are no longer visible. C) by the next day the ventricles, sulci and basal cisterns are totally obscured. 
When the brain is markedly swollen, successful intervention is less effective than in Stage I-II. ${ }^{13}$ Raised ICP indicates that the compensatory mechanisms have been exhausted and impairment of brain perfusion and herniation are imminent.

Noninvasive methods for determining intracranial pressure, notably transcranial Doppler using the pulsatility index have some value, but are inaccurate over a wide range of values and suffer the same limitations as direct ICP monitoring as an "early warning system" for detecting cerebral edema. ${ }^{14}$

Early sequential CT scans can be valuable diagnostic tool for patients who have significantly high level of INR or uncontrollable coagulopathy while waiting for liver transplantation. (Thus, we suggest that early and sequential CT scans are more sensitive than $\mathrm{CT}$ for cerebral edema and risk of serious progression). Computed tomogram can be used pre-emptively to institute treatment to offset severe cerebral edema and the risk of ischemia and herniation.

\section{Strengths and limitations of the study}

This study carries significant strength clinically. Early CT scans (within 24 hour) are sensitive to early brain parenchyma changes as shown by grey-white interface changes on initial CT scans. The results are more robust and predictive than hematological and biochemical tests. Initial and serial CT scans may obviate the need for ICP monitoring, which is often instituted too late in the illness in any case. Furthermore many patients cannot safely have ICP monitoring or decompression because of severe coagulopathy and systemic illness.

Our study is limited by its small sample size and retrospective nature. Few patients had serial CT scans. Ideally a multi-centre prospective study could be used to determine optimal monitoring and therapeutic strategies.

\section{REFERENCES}

1. Norenberg MD, Rao KV, Jayakumar KR. Mechanisms of ammoniainduced astrocytic swelling. Brain Metab Dis. 2005;20:303-18.

2. Jalan R, Olde Damink SW, Hayes PC, Deutz NE, Lee A. Pathogenesis of intracranial hypertension in acute liver failure: inflammation, ammonia and cerebral blood flow. J Hepatol. 2004;41:613-20.

3. Wendon JA, Harrison PM, Keays R, Williams R. Cerebral blood flow and metabolism in fulminant liver failure. Hepatology. 1994;19:1407-13.

4. Ware AJ, D'Agostino AN, Combes B. Cerebral edema: a major complication of massive hepatic necrosis. Gastroenterology. 1971;61:877-84.

5. Rashke RA, Curry SC, Rampe S, et al. Results of a protocol for the management of patients with fulminant liver failure. Crit Care Med. 2008;36:2244-8.

6. Casteldo ET, Chari RS. Liver transplantation for acute hepatic failure. HPB (Oxford). 2006;8(1):29-34.

7. Murphy N, Auzinger G, Bernel W, et al. The effect of hypertonic sodium chloride on intracranial pressure in patients with acute liver failure. Hepatology. 2004;39:464-70.

8. Mendez-Sanchez N, Chavez-Tapia NC, Espinoza B, et al. Acute liver failure and the Molecular Adsorbents Recirculating System: early experience in a tertiary care hospital in Mexico City. Ann Hepatol. 2004;3:164-6.

9. Akdogan M, Aladag M, Rashwan S, et al. Fulminant hepatic failure and the role of liver dialysis. In J Artif Organs. 2004;27:956-61.

7. Wiesner RH, McDiarmid SV, Kamath PS, et al. MELD and PELD application of survival models to liver allocation. Liver Transpl. 2001;7:567-80

8. Cholongitas EB, Betrossian A, Leandro G, et al. King's criteria, APACHE II and SOFA scores In acute liver failure. Hepatology. 2006;43:81-6.

9. Cholangitas E, Senzolo M, Patch D, et al. Review article: scoring systems for assessing prognosis in critically ill cirrhotics. Aliment Pharmacol Ther. 2006;24:453-64.

10. Wijdicks EFM, Plevak DJ, Rakela J, et al. Clinical and radiological features of cerebral edema in fulminant hepatic failure. Mayo Clin Proc. 1995 Feb;70(2):119-24.

11. Poulson J, Lee WM. AASLD position paper. The management of acute liver failure. Hepatology. 2005;41:1179-97.

12. Scorticati C, Prestifilippo FX, Castro JL, et al. Hyperammonemia, brain edema and blood-brain barrier alterations in prehepatic portal hypertensive rats and paracetamol intoxication. World $\mathbf{J}$ Gastroenterol. 2004;10:1321-4.

13. Vaquelo J, Fontana RL, Larson AM, et al. Complications and use of intracranial pressure monitoring in patients with acute liver failure and severe encephalopathy. Liver Transpl. 2005;12: 1581-9.

14. Zweifel C, Czosnyka M, Carrera E, et al. Reliability of the blood flow velocity pulsatility index for assessment of intracranial and cerebral perfusion pressures in head-injured patients. Neurosurg. 2012;7:853-61. 